\title{
State Voting Patterns in the 2016 Presidential Election and Uninsured Rates in Non-elderly Adults
}

J Gen Intern Med 35(9):2794-7

DOI: $10.1007 / \mathrm{s} 11606-020-05986-\mathrm{w}$

(c) Society of General Internal Medicine 2020

\section{INTRODUCTION}

Medicaid expansion and the health insurance "Marketplaces" of the Affordable Care Act (ACA) reduced the number of uninsured individuals to record lows in 2016. ${ }^{1}$ Uninsured rates may have since increased because of recent federal policies, including nullifying the individual mandate and reducing federal funding for Marketplace advertising and navigator programs. ${ }^{2}$ Even the expressed desires of congress and the President to repeal the ACA may have increased uninsured rates through a phenomenon known as "presidential cueing"3 by decreasing public support for the ACA, particularly in states with a plurality of Republican voters.

State-level policies may have enhanced or attenuated the impact of these federal actions on uninsured rates, with specific policies generally varying based on whether states have a plurality of Republican or Democratic voters. ${ }^{2,4}$ For example, some states have chosen to not expand Medicaid, ${ }^{2}$ and some states that initially expanded Medicaid have since applied for "Section 1115" waivers, which would allow for modifications to the Medicaid program such as the implementation of work requirements, that would effectively reduce enrollment. ${ }^{5}$ The degree to which states have devoted resources to Marketplace outreach and advertisement strategies to compensate for reduced federal funding also varies substantially along party lines. ${ }^{2,} 4$

Given the varying state responses to federal actions weakening the ACA, we conducted a descriptive study examining recent uninsured rates among adults aged 18-64, stratified by their states' voting patterns in the 2016 presidential election.

\section{METHODS}

We analyzed 2009-2018 data from the U.S. Census Bureau's Small Area Health Insurance Estimates, ${ }^{1}$ stratifying individuals based on their states' voting patterns. "Blue" $(N=21$, including Washington, DC) and "Red" $(N=24)$ states had a plurality of Democratic or Republican voters in both the 2012

Presentations None.

Received May 12, 2020

Accepted June 12, 2020

Published online July 7, 2020 and 2016 presidential elections, respectively. "Purple" states $(N=6)$ had a plurality of Democratic voters in 2012 and Republican voters in 2016; no Red states "flipped" to Blue in 2016. We compared the number and percent of uninsured individuals living in Blue, Red, and Purple states before and after the 2016 election.

\section{RESULTS}

From 2014 to 2016 (compared with 2013), uninsured adults aged 18-64 decreased by $15,803,039$ ( -8.3 percentage points [ppts]) overall (Fig. 1). Blue states saw a larger relative decrease in uninsured individuals during that period ( $-9.1 \mathrm{ppts}$; $7,658,286$ individuals) compared with those living in Purple ( -8.0 ppts; $2,981,026$ individuals) or Red states ( -7.7 ppts; $5,163,727$ individuals).

From 2017 to 2018 (compared with 2016), uninsured individuals increased by 853,474 (+ 0.3 ppts) overall. While Blue states saw a negligible 8,383 ( $-0.0 \mathrm{ppts})$ decrease in uninsured individuals, Purple and Red states saw increases of 241,475 (+ 0.5 ppts) and 620,382 (+ 0.7 ppts), respectively (Table 1$)$.

\section{DISCUSSION}

From 2017 to 2018, Red states experienced the largest increases in uninsured individuals followed by Purple states, while the numbers were stable for Blue states. The overall increase in uninsured individuals is noteworthy because it reverses a steady years-long trend.

This descriptive study precludes causal inferences, and there are important drivers of insurance rates we did not account for, such as employment rates and the economic and political realities at the local level. Nonetheless, the observed differential changes in uninsured individuals in Blue, Purple, and Red states are noteworthy, and may be partially explained by several factors. Most states that did not expand Medicaid were Red states. ${ }^{2}$ This is significant because, in non-expansion states, the Marketplaces represent one of the most important sources of insurance for those seeking coverage, especially low-income individuals. However, Marketplace coverage may be unaffordable to this segment given a lack of Marketplace subsidies for certain individuals below the poverty line (known as the Marketplace coverage gap ${ }^{6}$ ). Additionally, shortened open enrollment periods and the elimination of cost-sharing subsidies directly affect Marketplace plans. ${ }^{2}$ 


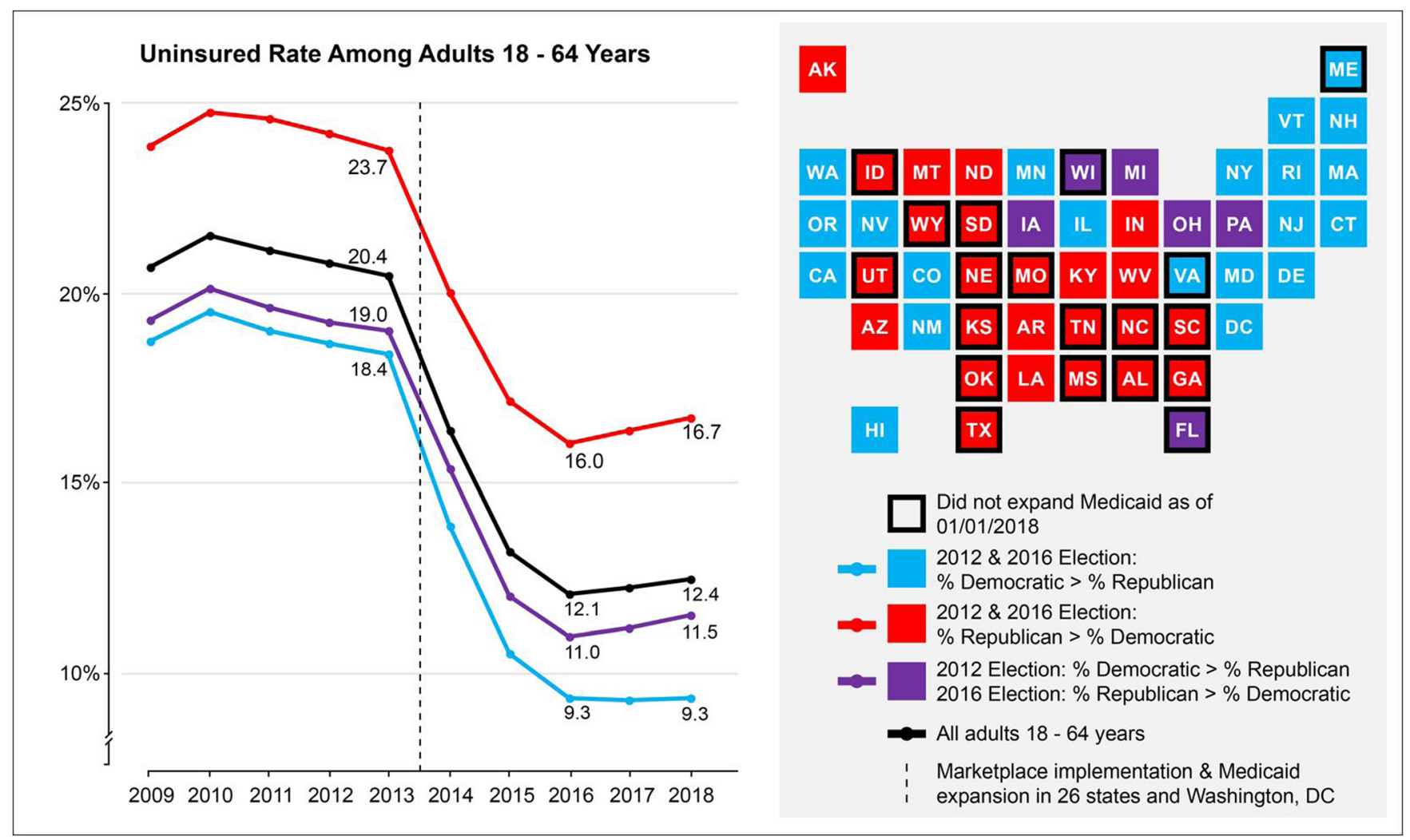

Figure 1 Uninsured rates among adults 18-64 years, stratified by state voting patterns. 


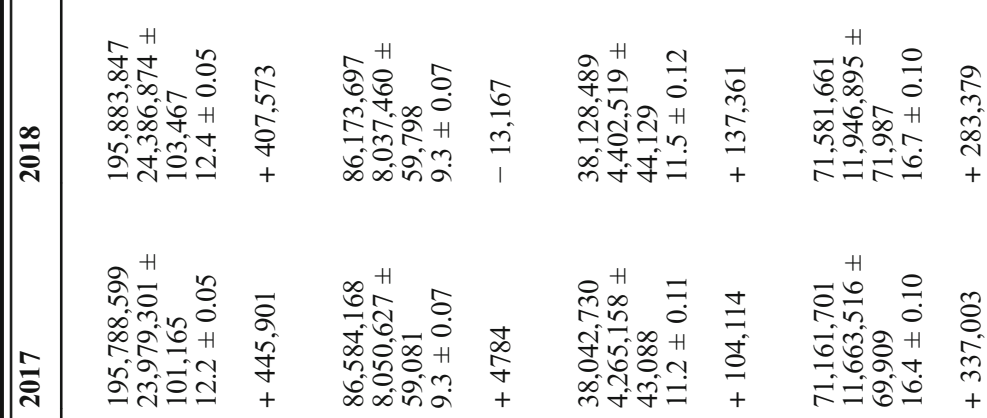

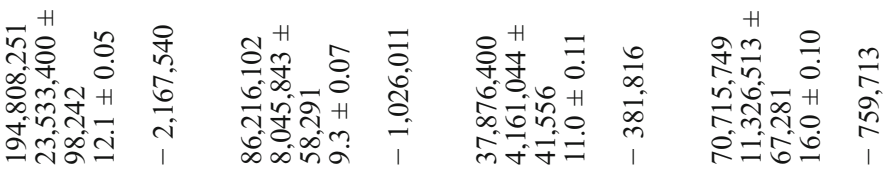

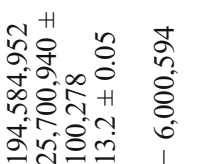

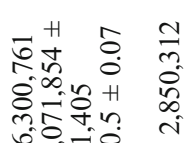

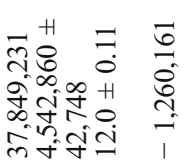

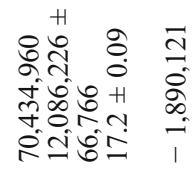

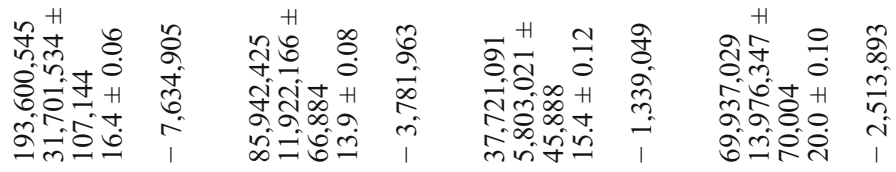

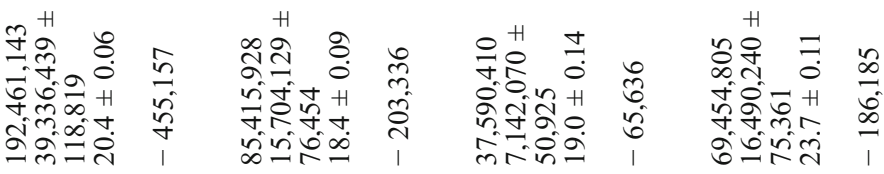

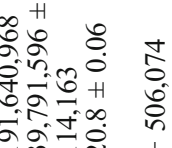

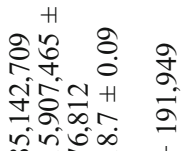

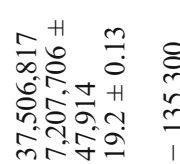

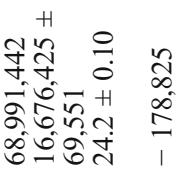

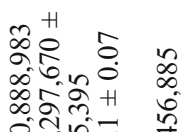

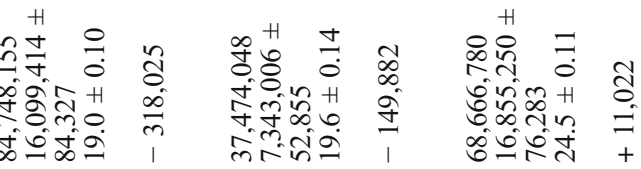

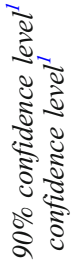

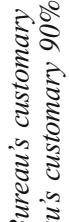

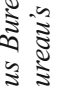

है

نे

ะू

ปี

离

ปั $\frac{2}{2}$

2.

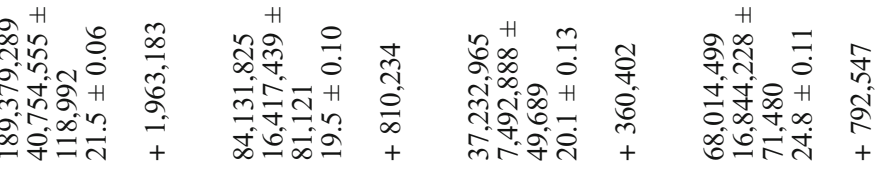

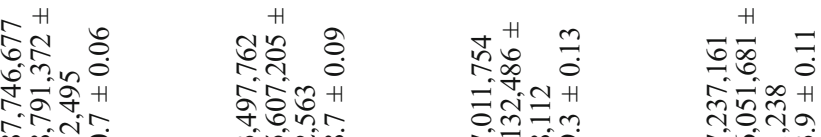

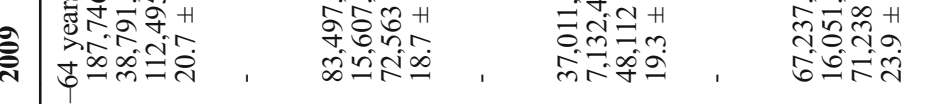

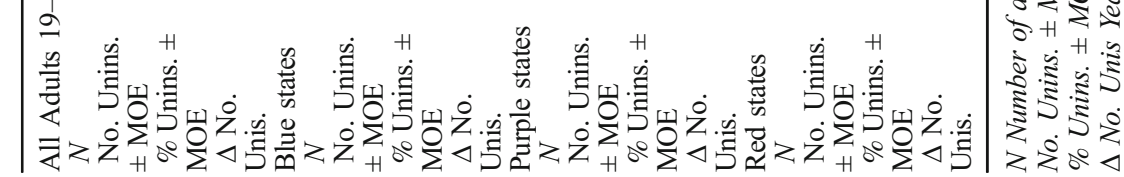


Substantial modifications to some states' Medicaid programs are being contemplated. Several Medicaid expansion states have applied for (and have been granted) Section 1115 waivers, with the majority of the waivers that would have the effect of decreasing Medicaid enrollment originating from Red states. ${ }^{5}$ Due to various legal challenges (and more recently COVID-19), these waivers have not yet been fully implemented. $^{5}$

Tracking the uninsured rate is vitally important as the policy landscape continues to evolve, and millions of people lose their jobs (and thus their health insurance) because of the COVID-19 pandemic. In particular, actions that further weaken the insurance Marketplaces and Medicaid enrollment could exacerbate already stark regional differences in insurance coverage.

Uriel Kim, $P h D^{1}$

Wyatt P. Bensken, $B S^{2}$

Johnie Rose, $\mathrm{MD}, \mathrm{PhD}^{1,3}$

Siran M. Koroukian, $\mathrm{Ph} \mathrm{D}^{2,3}$

${ }^{1}$ Center for Community Health Integration, Case Western Reserve University School of Medicine, Cleveland, Ohio, USA

${ }^{2}$ Department of Population and Quantitative Health Sciences, Case Western Reserve University School of Medicine,

Cleveland, Ohio, USA

${ }^{3}$ Population Cancer Analytics Shared Resource, Case Comprehensive Cancer Center,

Cleveland, Ohio, USA

Corresponding Author: Uriel Kim, $\mathrm{PhD}$; Center for Community Health Integration, Case Western Reserve University School of Medicine, Cleveland, Ohio, USA (e-mail: uxk13@case.edu).

\section{Funding Information}

- HHS, NIH, National Cancer Institute (NCI): Uriel Kim, Wyatt Bensken, Johnie Rose, Siran M Koroukian (P30 CA043703)

- Ohio Medicaid Technical Assistance and Policy Program (MEDTAPP): Siran M Koroukian
- HHS, NIH, Center for Scientific Review (CSR): Siran M Koroukian (R15 NR017792, UH3-DE025487)

- American Cancer Society (ACS): Siran M Koroukian 132678-RSGI 19-213-01-CPHPS

- Cleveland Clinical Foundation: Siran M Koroukian

- HHS, NIH, National Center for Advancing Translational Sciences (NCATS): Uriel Kim, Johnie Rose, (UL1TROOO439, 1TL1TROO2549)

- CWRU Center for Reducing Health Disparities: Uriel Kim, Johnie Rose

- CWRU Center for Community Health Integration: Uriel Kim, Johnie Rose

- HHS, NIH, National Institute of General Medical Sciences (NIGMS): Uriel Kim (5T32GM007250)

- Pharmaceutical Research and Manufacturers of America Foundation (PhRMA Foundation): Uriel Kim (PDHO18)

\section{Compliance with Ethical Standards:}

Conflict of Interest: Kim U, Bensken W, and Rose $J$ have no conflicts of interest to disclose.

Koroukian SM is supported in part from a grant from Celgene Corporation.

\section{REFERENCES}

1. Small Area Health Insurance Estimates (SAHIE) Program. https://www. census.gov/programs-surveys/sahie.html. Accessed May 3, 2020.

2. Thompson FJ, Gusmano MK, Shinohara S. Trump and the Affordable Care Act: Congressional Repeal Efforts, Executive Federalism, and Program Durability. Publius J Fed. 2018;48(3):396-424. https://doi.org/10. 1093/publius/pjy007.

3. Callaghan TH, Jacobs LR. The future of health care reform: what is driving enrollment? J Health Polit Policy Law. 2017;42(2):215-246. https://doi.org/10.1215/03616878-3766710.

4. Trachtman $\mathbf{S}$. When state policy makes national politics: the case of "obamacare" marketplace implementation. J Health Polit Policy Law. 2020;45(1):111-141. https://doi.org/10.1215/03616878-7893591.

5. Medicaid Waiver Tracker: Approved and Pending Section 1115 Waivers by State | The Henry J. Kaiser Family Foundation. https://www.kff.org/ medicaid/issue-brief/medicaid-waiver-tracker-approved-and-pendingsection-1115-waivers-by-state/\#note-0-2. Accessed May 3, 2020.

6. The Coverage Gap: Uninsured Poor Adults in States that Do Not Expand Medicaid | The Henry J. Kaiser Family Foundation. https://www.kff.org/ medicaid/issue-brief/the-coverage-gap-uninsured-poor-adults-in-statesthat-do-not-expand-medicaid/. Accessed February 22, 2020.

Publisher's Note: Springer Nature remains neutral with regard to jurisdictional claims in published maps and institutional affiliations. 